\title{
Mechanism of adaptability for the nano-structured TiAICrSiYN-based hard physical vapor deposition coatings under extreme frictional conditions
}

\author{
G. S. Fox-Rabinovich, ${ }^{1}$ J. L. Endrino, ${ }^{2}$ M. H. Agguire, ${ }^{3}$ B. D. Beake, ${ }^{4}$ S. C. Veldhuis, ${ }^{1}$ \\ A. I. Kovalev, ${ }^{5}$ I. S. Gershman, ${ }^{6}$ K. Yamamoto, ${ }^{7}$ Y. Losset, ${ }^{4}$ D. L. Wainstein, ${ }^{5}$ and \\ A. Rashkovskiy ${ }^{5}$ \\ ${ }^{1}$ Department of Mechanical Engineering, McMaster University, 1280 Main St. W. Hamilton, \\ Ontario L8S 4L7, Canada \\ ${ }^{2}$ Abengoa Research, Campus Palmas Altas, 41014 Seville, Spain \\ ${ }^{3}$ EMPA, Solid State Chemistry and Catalysis, CH-8600, Dübendorf, Switzerland \\ ${ }^{4}$ Micro Materials Limited, Willow House, Yale Business Village, Ellice Way, Wrexham, LL13 7YL, UK \\ ${ }^{5}$ Surface Phenomena Research Group, CNIICHERMET, 9/23, 2-nd Baumanskaya Street, \\ Moscow 105005, Russia \\ ${ }^{6}$ Russian Railway Research Institute, 10 Third Mytishchinskaya Street, Moscow 29851, Russia \\ ${ }^{7}$ Materials Research Laboratory, Kobe Steel Ltd., 1-5-5 Takatsuda-dai, Nishi-ku, Kobe, \\ Hyogo 651-2271, Japan
}

(Received 7 November 2011; accepted 11 February 2012; published online 20 March 2012)

\begin{abstract}
Recently, a family of hard mono- and multilayer TiAlCrSiYN-based coatings have been introduced that exhibit adaptive behavior under extreme tribological conditions (in particular during dry ultrahigh speed machining of hardened tool steels). The major feature of these coatings is the formation of the tribo-films on the friction surface which possess high protective ability under operating temperatures of $1000^{\circ} \mathrm{C}$ and above. These tribo-films are generated as a result of a selforganization process during friction. But the mechanism how these films affect adaptability of the hard coating is still an open question. The major mechanism proposed in this paper is associated with a strong gradient of temperatures within the layer of nano-scaled tribo-films. This trend was outlined by the performed thermodynamic analysis of friction phenomena combined with the developing of a numerical model of heat transfer within cutting zone based on the finite element method. The results of the theoretical studies show that the major physical-chemical processes during cutting are mostly concentrated within a layer of the tribo-films. This nano-tribological phenomenon produces beneficial heat distribution at the chip/tool interface which controls the tool life and wear behavior.Results of $\mathrm{x}$-ray photoelectron spectroscopy studies indicate enhanced formation of protective sapphire- and mullite-like tribo-films on the friction surface of the multilayer TiAlCrSiYN/TiAlCrN coating. Comprehensive investigations of the structure and phase transformation within the coating layer under operation have been performed, using high resolution transmission electron microscopy, synchrotron radiation technique: x-ray absorption near-edge structure and XRD methods. The data obtained show that the tribo-films efficiently perform their thermal barrier functions preventing heat to penetrate into the body of coated cutting tool. Due to this the surface damaging process as well as non-beneficial phase transformation (formation of AlN hex phase) drastically diminishes within the layer of the adaptive coating. Micro-mechanical properties measurements performed at room and elevated temperatures show that the hardness of the multilayer TiAlCrSiYN/TiAlCrN coating appears stable to $500{ }^{\circ} \mathrm{C}$ and then drops a little at $600{ }^{\circ} \mathrm{C}$ but still remains high. It means that if the surface tribo-films can reduce actual temperature down to this level the coating underneath is able to efficiently withstand heavy loads under operation. (C) 2012 American Institute of Physics. [http://dx.doi.org/10.1063/1.3693032]
\end{abstract}

\section{INTRODUCTION}

Wear of cutting tools is initiated by heavy mechanical loads applied (within a range of 1-5 GPa) on the cutting edge and friction generated heat as a result of intensive adhesive interaction at the tool/chip interface. ${ }^{1-3}$ The increase in cutting speed typical for modern high performance machining, especially under dry (coolant free) conditions leads to the temperature in the cutting zone increasing to $1000^{\circ} \mathrm{C}$ and above. ${ }^{1,4-6}$ The combination of heavy loads and high temperatures results in extreme tribological conditions during operation. The heat generated during cutting is unevenly distributed between the environment, workpiece, chip and cutting tools. Heat distribution in the cutting zone depends on the physical-chemical properties of the tool, workpiece materials, cutting conditions, tool design, and other external parameters. ${ }^{1}$ It is worth noting that in hard-to-cut materials such as hardened tool steels heat distribution in the cutting zone is not favorable, that results in high wear rate of cutting tools. ${ }^{7,8}$ PVD coatings are widely used to improve wear resistance of cutting tools. Modern hard nano-structured PVD coatings efficiently perform three major functions during cutting: protection against heavy mechanical loading and intensive surface damage, thermal barrier protection, and 
surface lubrication. ${ }^{9}$ Hard coatings are able to exhibit adaptive properties under operation. ${ }^{10}$ Due to this adaptation to the external stimuli the actual friction conditions shift to a milder mode that significantly reduces the wear rate. Protective/lubricating functions of the hard coating are strongly related to the phase transformation within the layer of surface coating in response to the environmental impacts. ${ }^{10}$ Various physical-chemical processes developing in the cutting zone are able to critically change properties of the tool surface. These processes are mainly responsible for adaptive behavior during tool life, with tribo-oxidation the most important process among them. ${ }^{10-12}$ Friction activates local plastic deformation, heat and associated with these processes external mass transfer of necessary elements of the coatings layer to the surface with the further tribo-chemical reactions at the tool/chip interface. The nano-scaled tribo-oxide films are dynamically generated and destroyed on the friction surface as a result of this self-organization process. ${ }^{12}$

Adaptive behavior and the related process of selforganization are strongly related to the gradient of characteristics within the entire system. Starting from a classic example of the self-organization process (Bernard cells), ${ }^{13}$ the temperature gradient critically affects various systems behavior, including tribo-systems, especially those working under severe and extreme high temperature/heavy loads conditions, such as cutting tools. With a thermally insulating coating, such as TiAlN-based coatings, heat flow to the substrate is impeded. ${ }^{14,15}$ More heat remains in the chip and dissipates via chip removal. The TiAlN family of coatings with high aluminum content is widely used for high performance machining applications. ${ }^{14}$ Systematic optimization of the composition of TiAlN-based coatings has resulted in the development of the synergistically alloyed TiAlCrSiYN mono- and multilayer coatings. ${ }^{16,17}$ The coatings, especially the multilayer, perform particularly well under severe/extreme tribological conditions. ${ }^{3,16,17}$ The adaptive behavior of these coatings develops with the formation of highly protective tribo-films with complex amorphous-crystalline structure ${ }^{3,10,16}$ on the friction surface during operation. Protective tribo-films formed on the surface of TiAlCrSiYN-based coatings have alpha-alumina-based sapphire as well as mullite crystal structures. ${ }^{3,16}$ Thermal conductivity of these oxide ceramic films at high temperatures is noticeably lower than the nitride coating layer. ${ }^{18,19}$ The thermal barrier properties of the hard coating system therefore depend on the properties of the coating layer by itself and, equally importantly, on the properties of the nano-scale layer of the tribo-films formed on the friction surface. Altogether, these characteristics can result in beneficial heat re-distribution during cutting.

The aim of this paper is to reveal the mechanism of adaptation of hard coating under extreme tribological conditions. A theoretical analysis of thermodynamic aspects of the friction phenomena combined with FEM modeling of the heat conduction in the cutting zone considering the affect of the tribo-films formation on the thermal barrier properties of the TiAlN-based PVD coatings during cutting has been performed. The results of these theoretical studies have been validated by experimental investigations on effect of the pro- tective tribo-films formation on the structure and phase transformation within the layer of the state-of-the-art TiAlCrSiYN-based coatings under extreme frictional conditions.

\section{THEORETICAL STUDIES}

According to the principle of dissipative heterogeneity ${ }^{, 20,21}$ a phenomenon of structural adaptation of tribomaterials occurs, which leads to the concentration of the significant part of the interactions between frictional bodies within the thin layer of the tribo-films (secondary structures) that generates during friction as a result of interaction with the environment.

We can present the energy balance of one of the frictional bodies in the following way:

$$
\mathrm{E}_{0}=\Delta \mathrm{U}+\mathrm{A},
$$

$\mathrm{E}_{0}$ - part of frictional energy that dissipates or stays in the frictional body (cutting tool);

A- energy dissipation during its transformation from the contact zone into the frictional body. In other words, this is a part of energy that accumulates and dissipates into the tribofilms (secondary structures);

$\Delta \mathrm{U}$ - change of the internal energy of the frictional body.

Previous studies ${ }^{16}$ have shown that for conditions with minimal wear rate during steady stage of wear,

$$
\frac{\Delta \mathrm{U}}{E_{0}} \rightarrow \min .
$$

From Eq. (1) follows that:

$$
\mathrm{A}=\mathrm{E}_{0}-\Delta \mathrm{U}(\mathrm{S}),
$$

$\mathrm{S}$ - entropy of the frictional body.

If $\mathrm{A}$ is differentiated by entropy of the final condition we obtain

$$
\frac{\partial \mathrm{A}}{\partial \mathrm{S}}=-\left(\frac{\partial \Delta \mathrm{U}}{\partial \mathrm{S}}\right)_{\mathrm{V}}=-\Delta \mathrm{T},
$$

$\mathrm{V}$ - volume of the body,

$\Delta \mathrm{T}$ - average temperature growths of the body (or near to the surface layers).

Part of the frictional energy that is going into the frictional body could be considered as a constant under unchanged values of load, speed, and the coefficient of friction. In the stationary process after formation of tribo-films, the energy that is going into the environment, for instance through the cutting tool, is equal to the energy that goes into frictional body. Therefore, part of the energy going from frictional body can be also considered as a constant and consequently the sum in (1) can be considered as constant as well.

As it follows from (2) we are mostly interested in the energy distribution between $\Delta \mathrm{U}$ and $\mathrm{A}$ in (1).

Differentiating is made at constant volume because the volume of worn surface layer is dramatically lower than the 
volume of the entire frictional body. That is why the volume could be considered as a constant.

It follows from (4) that value of A will decrease with the growth of $\mathrm{S}$ because $\Delta \mathrm{T}$ is positive. Reduction of value of $\mathrm{A}$ leads, as a consequence of (3), to the growth of $\Delta \mathrm{U}$ if value of $\mathrm{A}_{0}$ is constant. Therefore, ratio (2) will grow as well which could result in an increase in wear rate. Entropy grows for the system where the energy transfers from the heated to the less heated zone, so the maximal, most probable value of A (and therefore minimal wear rate) corresponds to the process with less possible growth of the entropy of the frictional body. Since the time of interaction at the same speed is a constant the requirement of less possible entropy growth transfers to the requirement of the less possible rate of the entropy growth.

During direct contact of the frictional bodies the rate of entropy growth at exchange of small amount of energy will be maximal (which corresponds to the maximal wear rate) and equal to

$$
\frac{d S}{d t}=\mathrm{q}\left(\frac{1}{\mathrm{~T}_{\mathrm{S}}}-\frac{1}{\mathrm{~T}_{\mathrm{C}}}\right)
$$

$\mathrm{q}$-heat flow; $\mathrm{T}_{\mathrm{S}}$ and $\mathrm{T}_{\mathrm{C}}$ - temperatures within the surface layers and contact surface correspondingly.

There is no practical energy dissipation for this kind of the interaction between frictional bodies and the process of friction develops into the catastrophic mode with subsequent surface damage. ${ }^{22-24}$ Similar to the Carnot cycle ${ }^{25}$ to reduce the rate of entropy growth it is necessary to introduce an intermediate body where the energy dissipation is taking place. In tribology, this intermediate body is the layer of tribo-films (secondary structures).

To reduce the rate of entropy growth the temperatures of the bodies that are exchanging energy have to be equal or close to equal. The secondary structures at the temperature $\mathrm{T}_{\mathrm{C}}$ have to receive energy from the contact zone isothermally. Part of this energy is spent on destruction, regeneration and heating of the secondary structures, and the rest of the energy transfers at the temperature $T_{S}$ into the body in the same isothermal way. During friction, the energy transfer is taking place constantly and therefore simultaneous equality of the secondary structures temperatures $T_{S}$ and $T_{C}$ could be achieved by means of the strong temperature gradient. The outer surface of the secondary structures has a temperature of $T_{C}$ and the secondary structure/frictional body interface has a temperature of $\mathrm{T}_{\mathrm{S}}$. The thickness and heat conductivity of the secondary structures has to be adjusted in the way to achieve the corresponding temperature gradient. This scheme is similar to the Carnot cycle, which is a typical reversible process and correspondingly it takes place with zero, in other words, minimal entropy change. In the case of high performance machining, while there is obviously no ideal process corresponding to the Carnot cycle, it appears that a tribosystem tries to develop a process with minimal entropy production by means of the formation of tribo-films (secondary structures).

Therefore, for compliance with condition of minimal wear rate from (2), the necessity of the third (intermediate) body formation, or in other words tribo-films, follows from (5). They are permanently generated and destroyed by friction. Simultaneously, these protective phases re-generate due to the corresponding processes of mass and energy transfer to the friction surface. If the rates of these processes are properly adjusted then the stationary state as well as the stability of secondary structures can be achieved.

Adaptability during friction is related to the formation of the stable tribo-films (secondary structures) on the friction surface. Stability of their formation is a results of Le-Chatelier-Brown principle generalized on the non-equilibrium state. ${ }^{19}$ The evolution of the tribo-system under operation is related to the formation of secondary structures on the friction surface. ${ }^{20}$ Therefore, the tribosystem without secondary structures is not stable against the external impact so if secondary structures are not generated then the tribo-system's operating conditions transforms to the catastrophic mode with deep surface damage. ${ }^{26}$ Formation of the tribo-films with highly protective properties and strong temperature gradient can prevent catastrophic behavior of the tribo-system that results in intensive surface damaging processes with corresponding intensive wear rate under extreme frictional conditions.

In the ideal case, the forming secondary structures receive energy from the source of friction in isothermal way and subsequently transfer it into the friction body similarly isothermally. The intensity of entropy growth decreases due to thermal transfer at the following interfaces: (1) source of friction/tribo-films and (2) tribo-films/frictional body.

This takes place at the difference in temperatures equal to zero in Eq. (1). However, a new source of entropy is forming, which is the energy dissipation into the layer of tribofilms (secondary structures). It is an internal source of entropy production. In other words, by means of tribo-films (secondary structures) formation, the system tries to substitute entropy growth due to the flow of entropy by entropy growth due to entropy production into the layer of tribofilms (secondary structures). The absolute value of this growth (under the same equal conditions) will be lower than the entropy flow in the absence of the tribo-films on the friction surface so the wear rate should decrease as well. ${ }^{24,26}$

\section{A. FEM modeling of heat conduction in the cutting zone with formation of the tribo-films at the cutting tool/chip interface}

According to Ref. 27, the maximal frictional heating arises within $1 / 3$ of a total contact length between a chip and a tool (Fig. 1(a). Figure 1(b) shows one of the meshes used in the numerical simulation formed by triangular elements. Figures 1(a) and 1(b) show a typical contact area on the toolchip interface and the area used in the numerical simulation in the present work (approximately $1.5 \mathrm{~mm}^{2}$ ). The thermal profile in this volume has been investigated using a FEM model of the cutting tool with film of various protective tribo-oxides formed during friction on the surface of the hard TiN and TiAlN-based coatings, such as alumina $\left(\mathrm{Al}_{2} \mathrm{O}_{3}\right)$ and mullite $3\left(\mathrm{Al}_{2} \mathrm{O}_{3}\right) 2\left(\mathrm{SiO}_{2}\right)$ tribo-oxides (Table I). An idealized coating system with uniform structure, hemispherical area of 


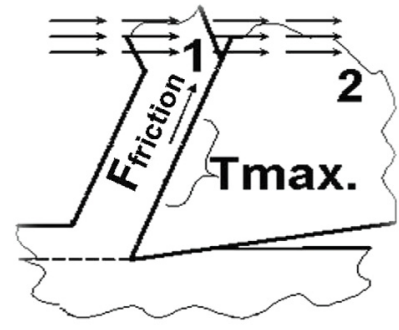

a

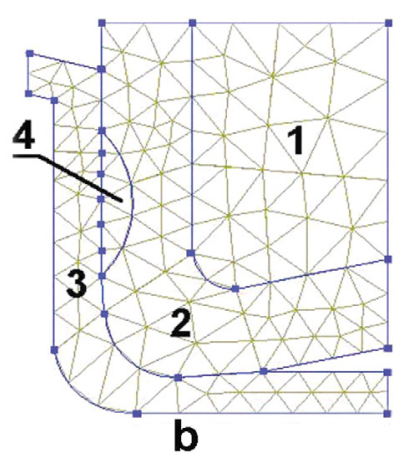

FIG. 1. (Color online) The scheme (a) and FEM mesh (b) of area with maximal heating at a chip/tool interface during cutting: (a) 1-chip, 2-cutting tool; (b) 1-carbide tool; 2-PVD coating; 3-chip (steel); 4-tribo-oxides.

tribo-oxides is analyzed to investigate the heat transport across the barrier layer of the tribo-films and the coating. The effect of protective tribo-film formation on the heat transfer has been investigated. The objective of this modeling is to study the heat conduction in the cutting zone.

The following hypotheses were considered in the present analysis: 2D geometrical domain; transient regime; absence of radiation models; constant density $(\rho)$, constant or variable specific heat $(\mathrm{Cp})$ and temperature dependent thermal conductivity coefficients; perfect thermal contact and no thermal resistance between the coating layer and the substrate material; uniform and time-dependent boundary conditions of the heat flux $q^{\prime \prime}(t)$. For the solution of the continuity, momentum, and energy equations the fluid dynamics calculus is employed using the finite volume method (FVM) with Eulerian scheme for the spatial and temporal discretization of the physical domain with a finite number of control volumes. ${ }^{28-33}$

The thermal model of heat conduction and its regions for the imposition of the boundary conditions in 2D coated tools are presented in Fig. 1(b). The area 2, shown in Fig. 1(b), is the hard PVD coatings with the thickness of $2 \mu \mathrm{m}$ and area 1 is the cemented carbide cutting tool substrate. The area 4 exhibits the area of the tribo-oxides formation at the chip/coated tool interface. For calculation purposes only, the thickness of this film is strongly exaggerated in our model. In reality, the dynamically re-generating tribo-oxides has a complex amorphous-crystalline and the thickness within 0.1$0.01 \mu \mathrm{m} .{ }^{34}$ The heat diffusion equation is subject to the following boundary conditions: imposed heating at $1393 \mathrm{~K}$ in 7 nodal points of area 4 at the inter-phase between areas 1 and 2 (chip/tool interface), and constant convection on the external surfaces in the remaining regions of the cutting tool. The thermal parameters of the materials investigated, both for the substrate and the coating, under ambient temperature are presented in Table I. The chemical composition of the nitride coatings affects their heat conductivity. ${ }^{15}$ For many of coatings this difference is insignificant at room temperature and can differ noticeably at high temperatures. ${ }^{15}$ Temperature dependence of the heat conductivity coefficient mainly determines the thermal barrier properties of the coating and the tribo-oxide films. Heat conductivity of TiAlN-based coatings reduces with growth of AlN nano-phase content. ${ }^{15}$ While in general the nitride coating layers raise their own heat conductivity during heating, ${ }^{15,19}$ in contrast, the alumina dramatically reduces its own heat conductivity from 40 (Wm-1 $\mathrm{K}-1)$ up to $3(\mathrm{Wm}-1 \mathrm{~K}-1)$ as the temperature is increased from 293 to $1393 \mathrm{~K}^{19}{ }^{19}$ Aluminum oxide therefore efficiently protects the tool surface from overheating. For mullite tribofilms this trend is even stronger. This thermal conductivity coefficient for mullite thin films decreases from 6.86 (Wm-1 $\mathrm{K}-1)$ at $100 \mathrm{~K}$ down to $0.19-0.26$ at high temperatures. ${ }^{35} \mathrm{In}$ earlier publications, the nitride coatings (with various compositions) did not show significant affect on the thermal isolation of the cemented carbide substrate. ${ }^{28,31,32}$ On the other hand, if the coating has an alumina thermal barrier layer, then it has impact on the heat distribution within the cutting zone. ${ }^{36-43}$ In the earlier investigations, ${ }^{28,31,32}$ the process of tribo-oxidation with formation of protective tribo-films and the different temperature dependencies of the thermal conducting coefficients for the tribo-films (Table I) were not taken into consideration. The formation of the protective oxides strongly affects wear behavior (Fig. 2(1)). As can be seen from the comparison of Figs. 2(1), 2(2), and 2(3) the alumina tribo-films greatly reduce the heat going into the cutting tool as compared to the uncoated tools and the tool with (non-protective at high temperatures) rutile tribofilms and plays a role of the thermal barriers layer that transfers most part of the heat flow into the chip (Fig. 2(3)). The results indicate that the $(\mathrm{TiAl}) \mathrm{N}$ coatings with an $\mathrm{Al}_{2} \mathrm{O}_{3}$ tribo-oxide layer significantly change the temperature gradients at the tool/chip interface and the tool substrate. Formation of mullite tribo-films additionally improves thermal barrier properties of the coated tool surface (Figs. 2(4)). Due to thermal barrier properties of the tribo-films, the physical chemical processes are concentrated within a very thin surface contact layer resulting in a dramatic reduction of the depth of the layer of actual chip/tool interaction. The processes of the mass transfer and plastic deformation are concentrated within the thin surface layers.

TABLE I. Thermal properties of the coatings and tribo-films.

\begin{tabular}{|c|c|c|c|c|}
\hline Material & $\begin{array}{l}\text { Density, } \\
\rho \mathrm{Kg} / \mathrm{m}^{-3}\end{array}$ & $\begin{array}{l}\text { Specific heat, } \\
\mathrm{Cp}, \mathrm{J} \mathrm{kg}^{-1} \mathrm{~K}^{-1}\end{array}$ & $\begin{array}{l}\text { Coefficient of thermal } \\
\text { conductivity, } \mathrm{k}, \mathrm{W} \mathrm{m} \mathrm{m}^{-1} \mathrm{~K}^{-1}\end{array}$ & Reference \\
\hline WC-Co cemented carbide tool with Co content of $6 \%$ & 14900 & 200 & 130 , at $25^{\circ}(\mathrm{C})$ & $(23-24)$ \\
\hline Steel (workpiece) & 7900 & $\mathrm{Cp}=173.524+0.345^{*} \mathrm{~T}$ & $\mathrm{k}, \mathrm{f}(\mathrm{T})=33.34+0.01863 * \mathrm{~T}$ & $(33,34)$ \\
\hline AlTiN coating & 4650 & 645 & $\mathrm{k}, \mathrm{f}(\mathrm{T})=25.21+0.00127 * \mathrm{~T}-0.00000029 * \mathrm{~T}^{2}$ & $(25,26)$ \\
\hline Alumina $\left(\mathrm{Al}_{2} \mathrm{O}_{3}\right)$ film & $3780-3880$ & 1079 & $\mathrm{k}, \mathrm{f}(\mathrm{T})=40.0-0.0495^{*} \mathrm{~T}+0.000017 \mathrm{~T}^{2}$ & $(25,27)$ \\
\hline Mullite $3\left(\mathrm{Al}_{2} \mathrm{O}_{3}\right) 2\left(\mathrm{SiO}_{2}\right)$ film & $316 \ldots 322$ & & $\mathrm{~K}=0.19 \ldots 0.26$ (for thermally sprayed mullite) & $(14)$ \\
\hline Rutile $\mathrm{TiO}_{2}$ film & 3780 & 680 & anisotropic $\mathrm{k}=6.69 \ldots 12.55$ & (33) \\
\hline
\end{tabular}


FEM modeling has shown that tribo-films formed on the coatings additionally significantly improve thermal barrier properties of the surface engineered layer. The formation of these causes beneficial heat flow re-distribution that largely prevents heat propagation into the body of the tool.

\section{EXPERIMENTAL}

The nano-multilayered $\mathrm{Ti}_{0.2} \mathrm{Al}_{0.55} \mathrm{Cr}_{0.2} \mathrm{Si}_{0.03} \mathrm{Y}_{0.02} \mathrm{~N} /$ $\mathrm{Ti}_{0.25} \mathrm{Al}_{0.65} \mathrm{Cr}_{0.1} \mathrm{~N}$ coating was deposited using $\mathrm{Ti}_{0.2}$ $\mathrm{Al}_{0.55} \mathrm{Cr}_{0.2} \mathrm{Si}_{0.03} \mathrm{Y}_{0.02}$ and $\mathrm{Ti}_{0.25} \mathrm{Al}_{0.65} \mathrm{Cr}_{0.1}$ targets fabricated by powder metallurgical process on a mirror polished cemented carbide WC-Co substrate and ball nose end mills in a R\&D-type hybrid PVD coater (Kobe Steel Ltd.) using a plasma-enhanced arc source. Samples were heated up to about $500{ }^{\circ} \mathrm{C}$ and cleaned through $\mathrm{Ar}$ ion etching process. $\mathrm{Ar}-\mathrm{N}_{2}$ mixture gas was fed to the chamber at a pressure of 2.7 $\mathrm{Pa}$ with a $\mathrm{N}_{2}$ partial pressure of $1.3 \mathrm{~Pa}$. The arc source was operated at $100 \mathrm{~A}$ for a $100 \mathrm{~mm}$ diam $\times 16 \mathrm{~mm}$ thick target. Two targets were used for coating deposition. Other deposition parameters were as follows: bias voltage: $100 \mathrm{~V}$; substrate rotation: $5 \mathrm{rpm}$. The thickness of the coating was around 2 microns for the film characterization and cutting test work. The TiAlCrSiYN-based coatings have mainly B1

\section{Temperature profiles}
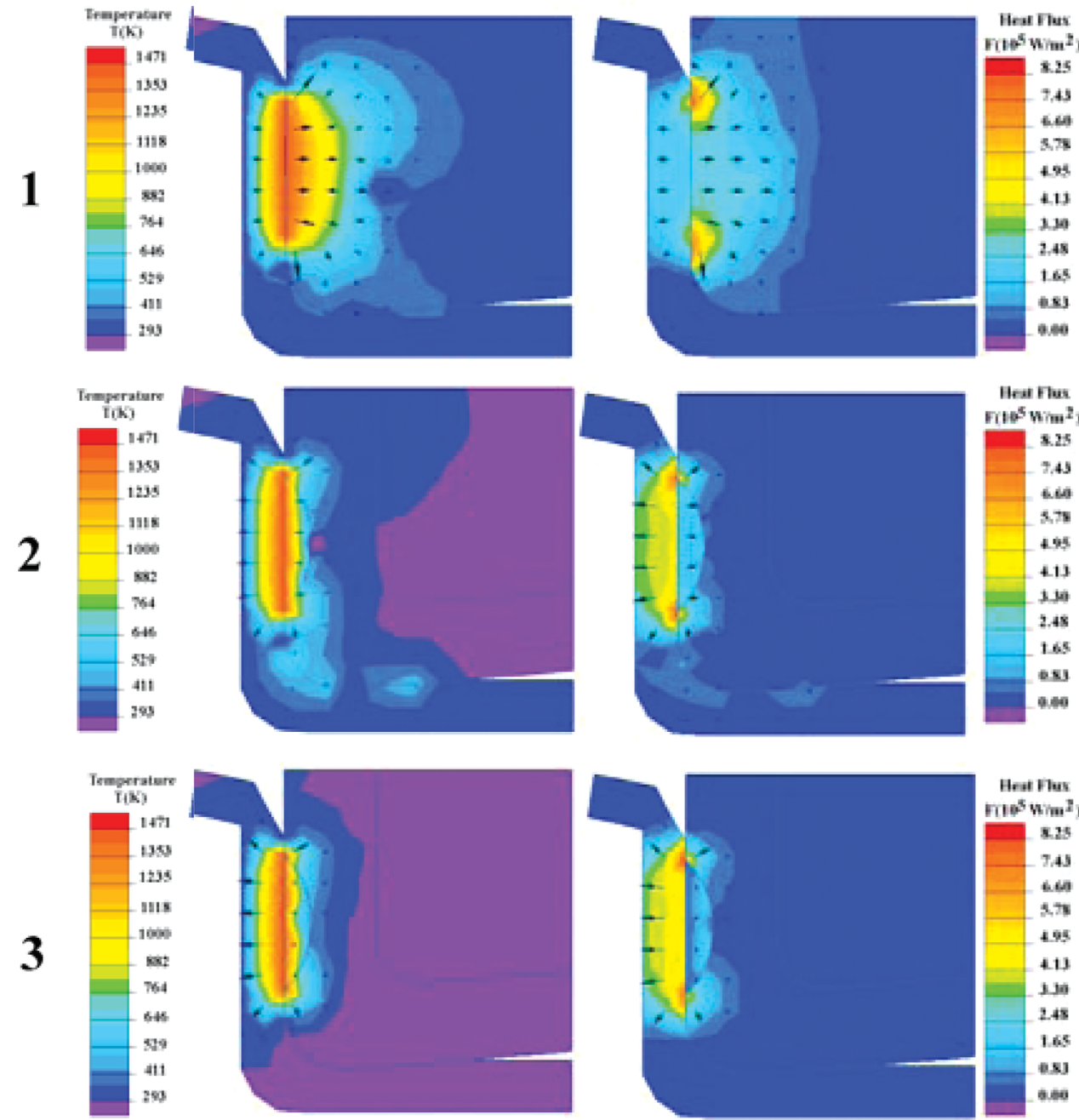

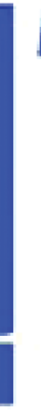

\section{Heat fluxes}
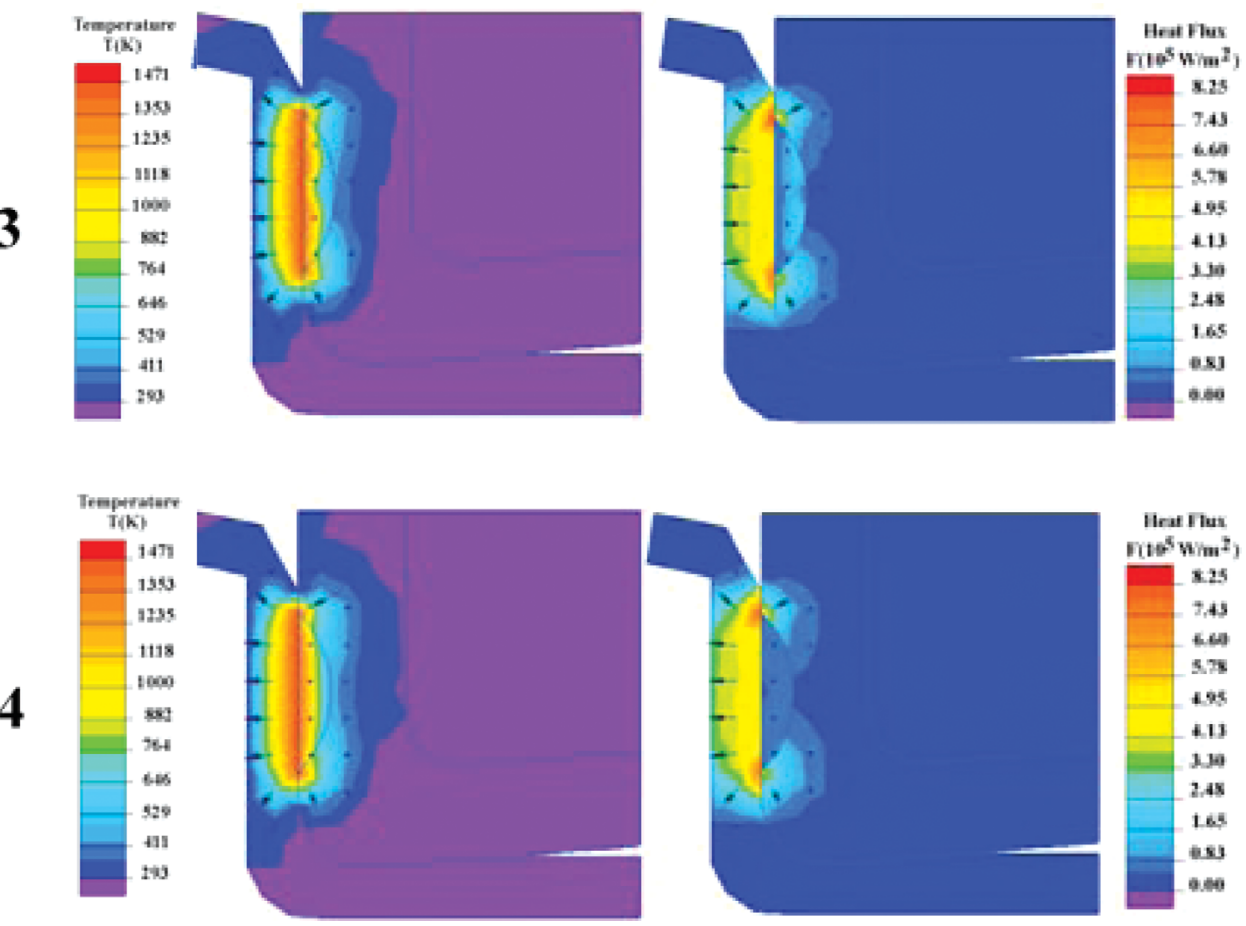

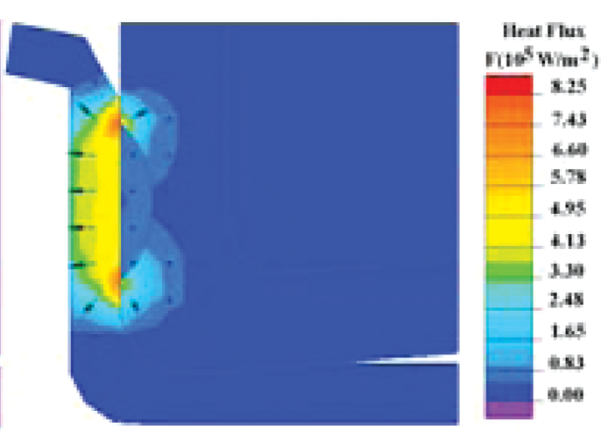

FIG. 2. (Color online) The temperature profiles (in $\mathrm{K}$ ) and heat flux maps in the cemented carbide cutting tool (1) uncoated carbide without tribo-films formation; (2) tool with TiN-based coating with rutile tribo-films formation; (3) tool with TiAlN-based coating with alumina tribo-films formation; (4) and tool with TiAlSiN-based coating with mullite tribo-films on the friction surface (stable stage of wear, after $200 \mathrm{~s}$ of cutting). 
crystal structure and nano-scale grain size below $40 \mathrm{~nm} .^{3,16}$ The multilayer coating has a complex structure that combines nanomultilayer structure with modulating composition and columnar structure. Multilayer period is $20-40 \mathrm{~nm} .^{16,17}$ Cross-sectional TEM observation was employed in combination with focused ion beam (FIB) for investigation of the coatings on the cemented carbide WC/Co substrates. Transmission electron microscopy and selected area electron diffraction (SAED) were performed in a JEOL FS2200 microscope at an acceleration voltage of $200 \mathrm{kV}$. High annular angular dark field (HAADF)-STEM imaging of the coating was employed with EDAX profile of the coating layer (beam of $1 \mathrm{~nm}$ spot size).
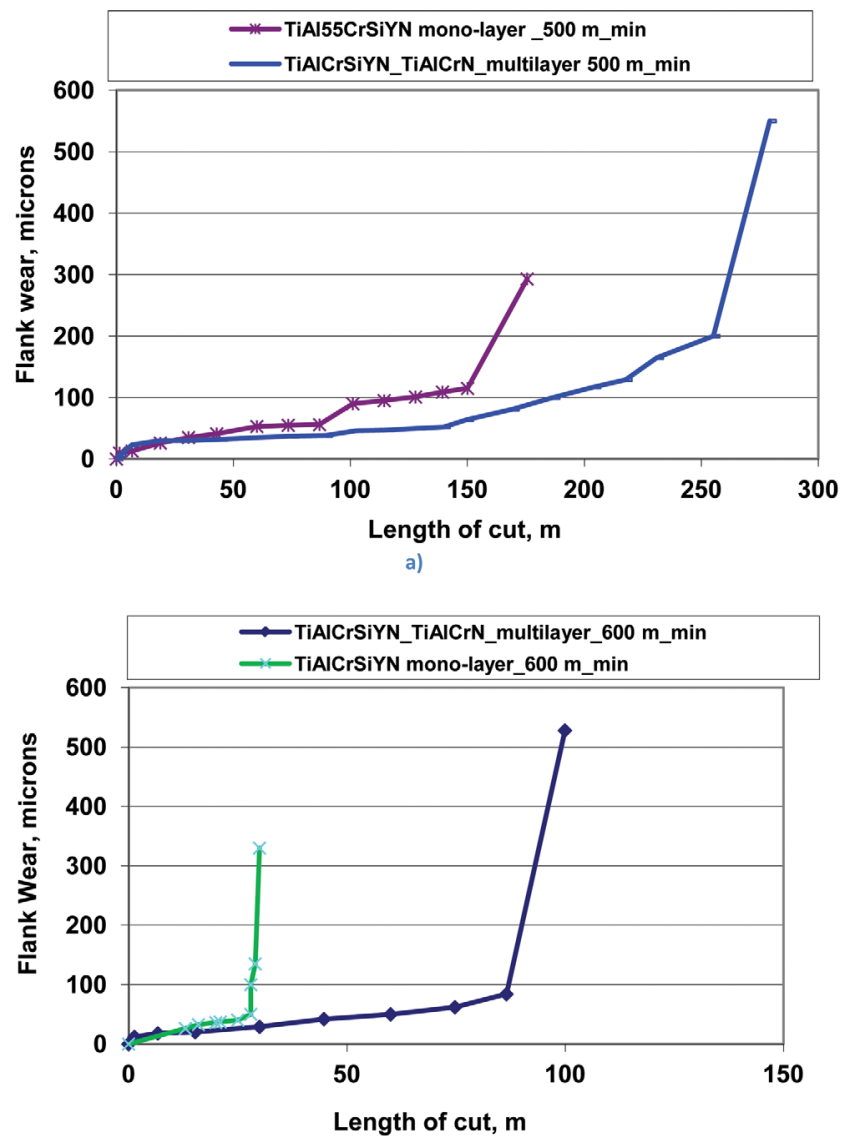

b)

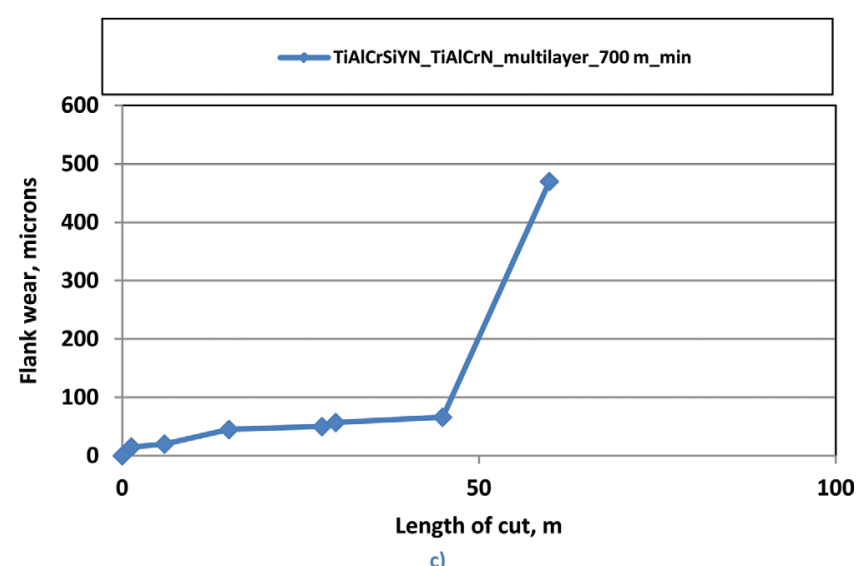

FIG. 3. (Color online) Tool life of TiAlCrSiYN-based mono- and multilayer coatings vs cutting speed: (a) $500 \mathrm{~m} / \mathrm{min}$; (b) $600 \mathrm{~m} / \mathrm{min}$; (c) $700 \mathrm{~m} / \mathrm{min}$.
The structural and phase transformations at the cutting tool/workpiece interface and the chemical composition of the tribofilms formed were studied by x-ray photoelectron spectroscopy (XPS) with a ESCALAB MK2 (VG) electron spectrometer equipped with a hemispherical energy analyzer. The $\mathrm{x}$-ray tube with monochromatic $\mathrm{Al} \mathrm{K}_{\alpha}$ radiation $(\mathrm{h} \nu=1486.6 \mathrm{eV})$ was used as an excitation source. The sector $0.5 \times 5.0 \mathrm{~mm}$ was selected for surface analysis. The $\mathrm{XPS}$ signal was recorded in the mode $\mathrm{CAE}=50.0 \mathrm{~V}$ at 0.25 $\mathrm{eV} / \mathrm{s}$.

Owing to its elemental and local character selectivity, synchrotron radiation techniques such as $\mathrm{x}$-ray absorption near-edge structure (XANES) have been successfully
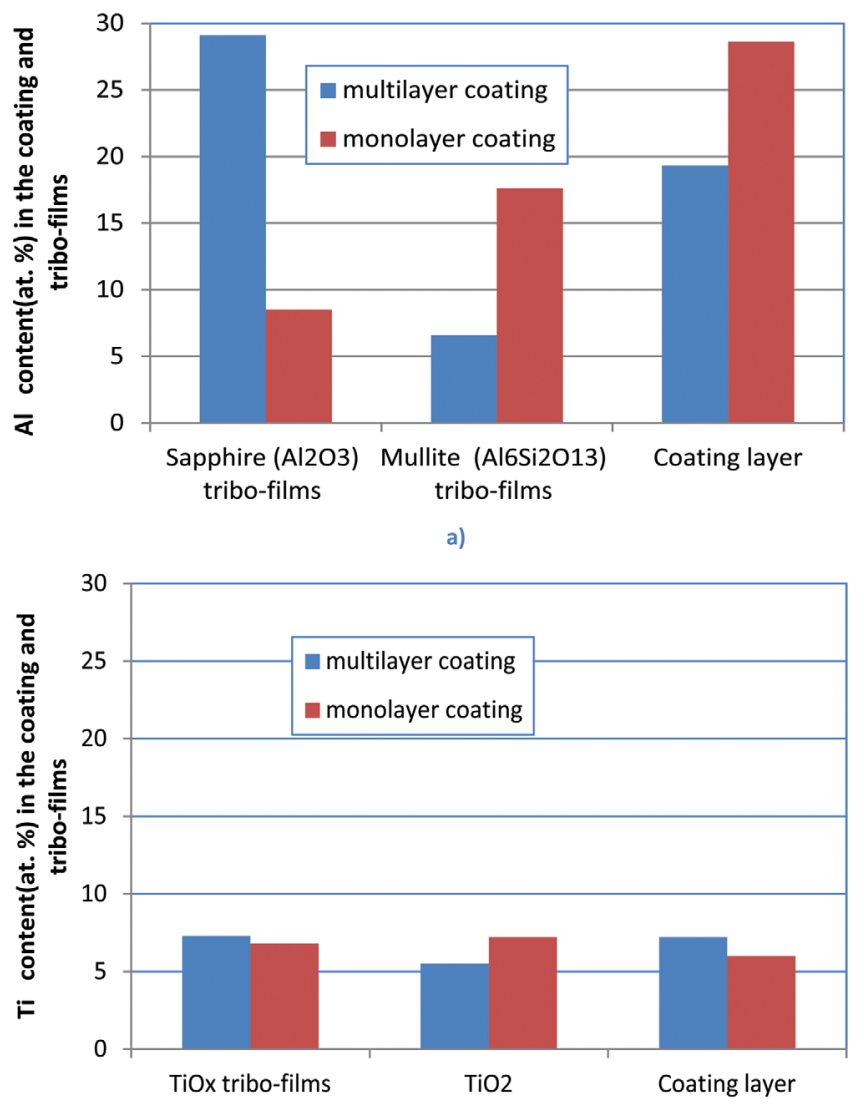

b)

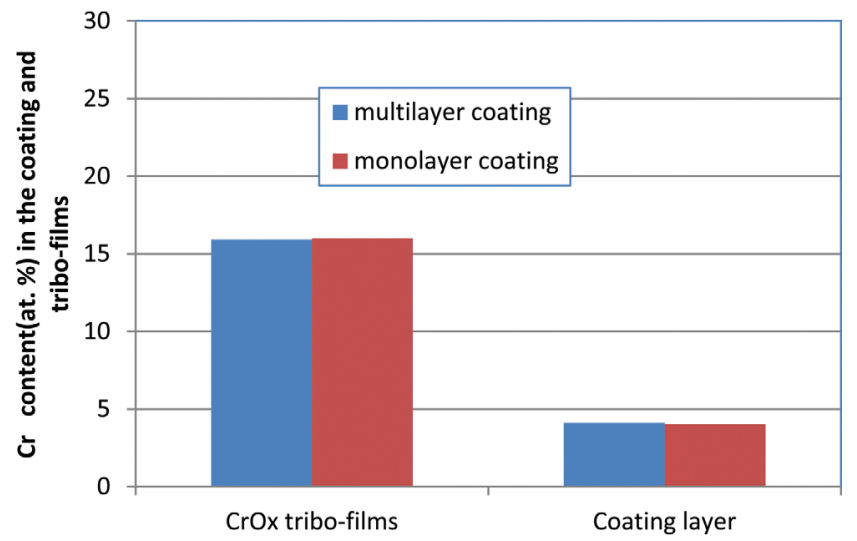

c)

FIG. 4. (Color online) Phase and chemical composition of the worn surface (XPS data): ${ }^{12}$ (a) Al-O tribo-films; (b) Ti-O tribo-films; (c) Cr-O tribo-films. 


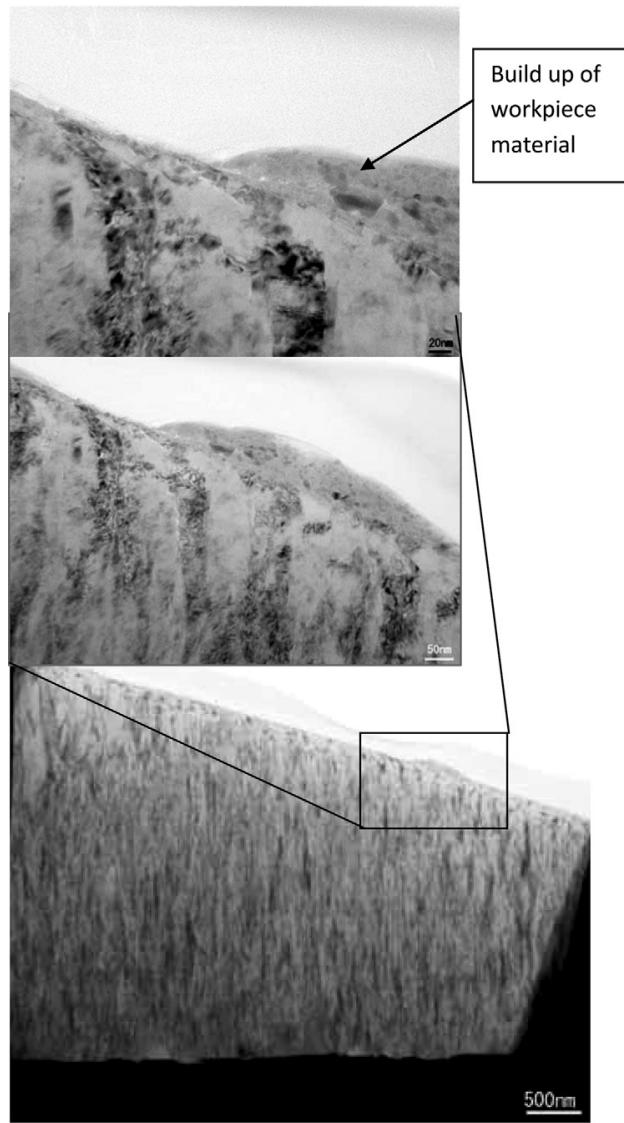

a)

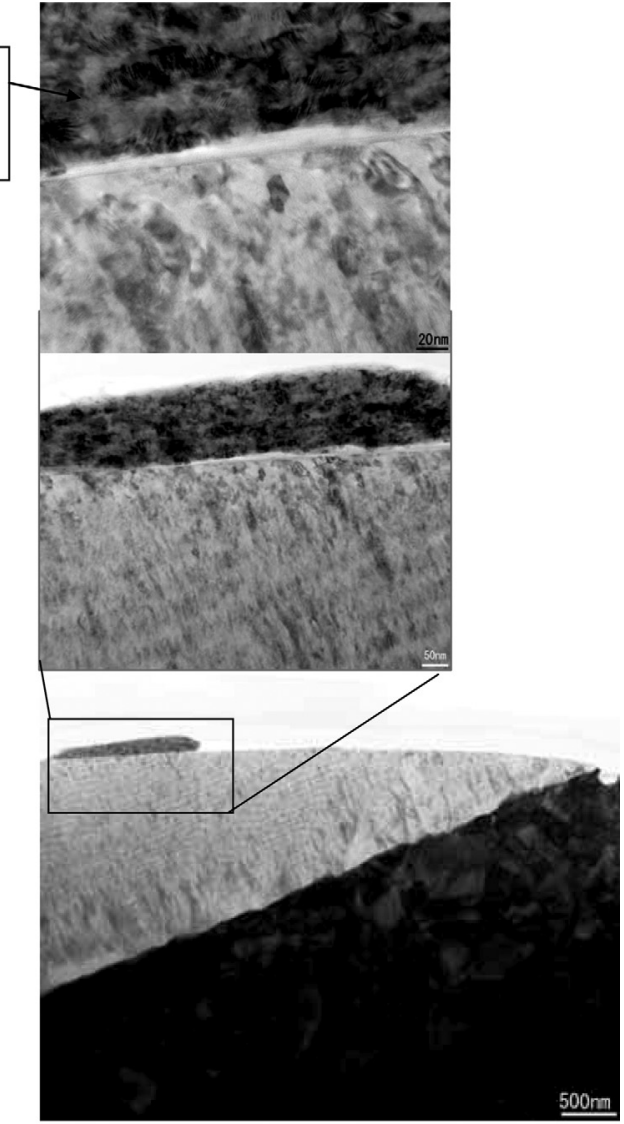

b)
FIG. 5. TEM image (cross-sectional views at various magnifications) of the worn coated ball-nose end mills with (a) TiAlCrSiYN mono-layered and (b) TiAlCrSiYN/TiAlCrN multi-layered coatings. employed to perform structural studies of hard nitride coatings. ${ }^{44-46}$ XANES experiments were carried out at the SGM beamline at the Canadian Light Source. The beamline has a "Dragon"-type spherical grating monochromator, with the attendant required exit slit tracking with a spot size of
$0.5 \mathrm{~mm} \times 0.5 \mathrm{~mm}$. The equipment allows for a physical travel upper limit to the energy range at around $2050 \mathrm{eV}$ and a resolution up to $10^{4}$.

The micro-mechanical characteristics of the coatings were measured on WC-Co using a Micro Materials NanoTest

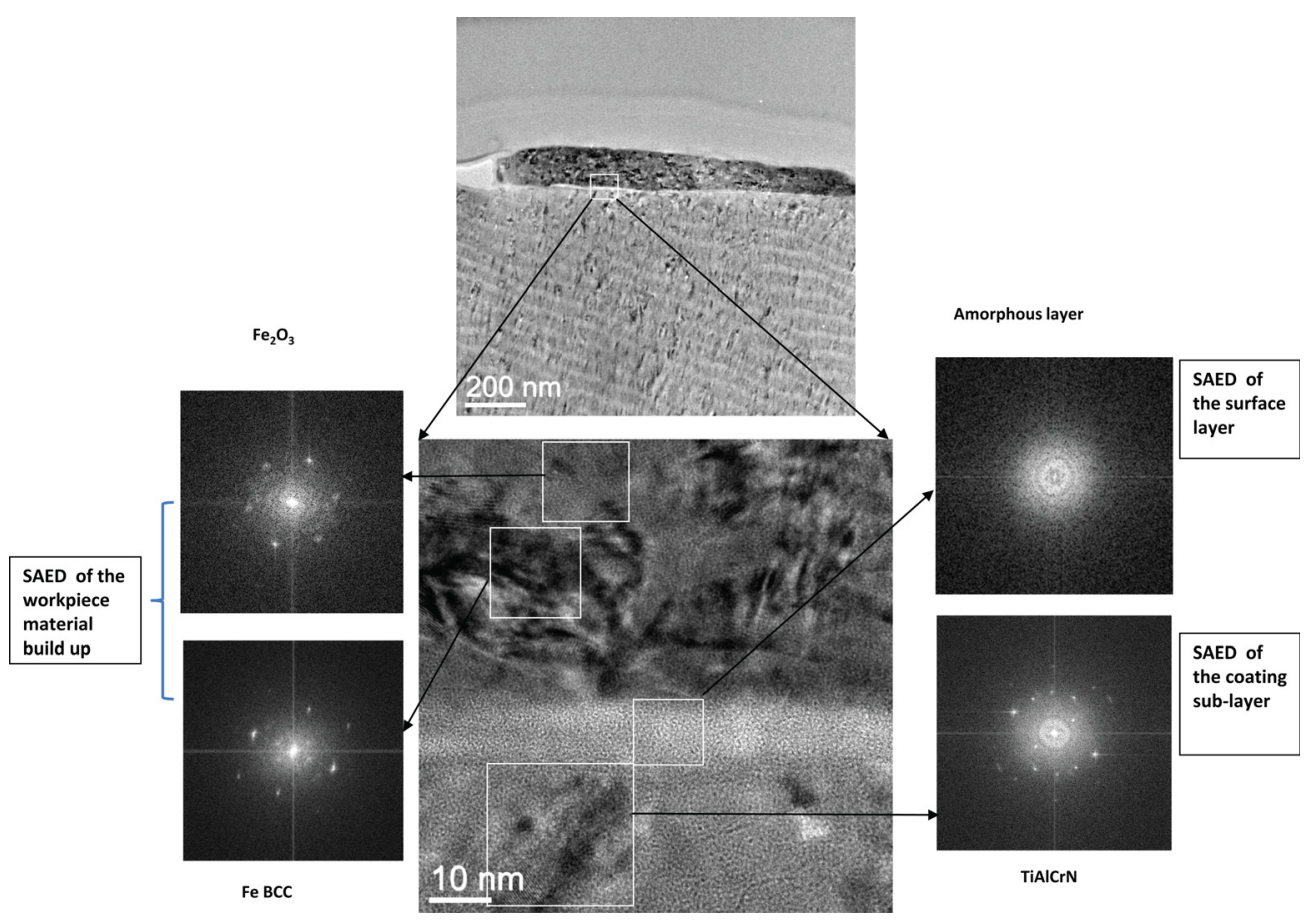

FIG. 6. (Color online) TEM image of the worn tool with TiAlCrSiYN/TiAlCrN multilayer coating: FIB cross-sectional view with SAED pattern insets. 
system. Nanoindentation was performed in a load controlled mode with a Berkovich c-BN indenter calibrated for load, displacement, frame compliance, and indenter shape according to an ISO14577-4 procedure. The area function for the indenter was determined by indentations to $0.5-500 \mathrm{mN}$ into a fused silica reference sample. For the nanoindentation into the coatings, the peak load was $40 \mathrm{mN}$ and up to 40 indentations were performed for each coating at each temperature. This load was chosen to minimize any influence of surface roughness on the data while ensuring that the indentation contact depth was under $1 / 10$ film thickness so that a coating-only (load-invariant) hardness could be measured in combination with coating-dominated elastic modulus. Nanoindentation was performed at room and elevated temperatures up to $600^{\circ} \mathrm{C}$. For the high temperature experiments, both the sample and indenter were heated separately to ensure isothermal contact. The loading and unloading rates were both $2 \mathrm{mN} / \mathrm{s}$. Loading to $40 \mathrm{mN}$ was in $20 \mathrm{~s}$. There was a hold time at peak load of $10 \mathrm{~s}$. Hold at $90 \%$ unloading was $60 \mathrm{~s}$ for thermal drift correction. There was no influence of the temperature on the reliability of the hardness measurements. ${ }^{47}$ The scatter in hardness measurements at room temperature and up to $600^{\circ} \mathrm{C}$ was around $\sim 15 \%$.

Cutting tests have been performed during dry ball-nose end milling (Mitsubishi carbide end mills, $\mathrm{D}=10 \mathrm{~mm}$ ) of the hardened AISI H13 tool steel with hardness HRC 53-55 under strongly intensifying cutting conditions. The cutting experiments were carried out on a three-axis vertical milling center (Matsuura FX-5). The cutting parameters were: speed 400-700 m/min; feed: $0.06 \mathrm{~mm} / \mathrm{tooth}$; axial depth: $5.0 \mathrm{~mm}$; radial depth: $0.6 \mathrm{~mm}$. The coated tool flank wear was measured using an optical microscope (Mitutoyo model TM). A tool dynamometer (9255B, Kistler) was used to measure the cutting forces. At least three cutting tests were performed for each kind of coatings under corresponding operations. The scatter of the tool life measurements was approximately $10 \%$.

\section{RESULTS AND DISCUSSION}

The tool life and wear behavior of two state-of-art TiAlCrSiYN-based coatings has been compared during high speed ball nose end milling of hardened $\mathrm{H} 13$ tool steel. Tool life of the adaptive TiAlCrSiYN monolayer and TiAlCrSiYN/TiAlCrN multilayer coatings versus cutting speed is presented in Figs. 3(a) and 3(b). The tool life data shows that the TiAlCrSiYN/TiAlCrN multilayer coating significantly outperforms the TiAlCrSiYN monolayer coating within the range of cutting speeds of $500-700 \mathrm{~m} / \mathrm{min}$. This takes place mainly due to difference in the characteristics of the tribofilms formed on the friction surface (Fig. 4).

To study characteristics of the tribofilms, XPS analysis of the worn tool surface was performed. ${ }^{16}$ A partial chemical transformation of aluminum in the coating is taking place which is more intensive in multilayer coating: $19.3 \%$ of $\mathrm{Al}$ is retained in the complex nitride, $6.6 \%$ of aluminum oxidizes with formation of complex Al-Si-O oxide (mullite), 29.1\% aluminum oxidizes with the formation of $\mathrm{Al}_{2} \mathrm{O}_{3}$ (sapphire), ${ }^{16}$ which is two times higher compared to the mono-layered coating (Fig. 4(a)). The formation of $\mathrm{Al}-\mathrm{Si}-\mathrm{O}$ bonds in $\mathrm{Al}_{6} \mathrm{Si}_{2} \mathrm{O}_{13}$ mullite tribo-films can also be identified. ${ }^{48-50}$ The overall amount of protective tribo-films (sapphire and mullite) is higher in multilayer coating (Fig. 4(a)). Significant amounts (around 16\%) of lubricating ${ }^{51}$ polyvalent chromium oxides are also generated on the surface of the coatings (Fig. 4(c)). The non-stoichiometric titanium tribo-oxide (7.3\%) and rutile $\mathrm{TiO}_{2}(5.5 \%$, Fig. 4(b)) form on the friction surface as well. Only small amount of $\mathrm{Si}-\mathrm{O}$ phase has been identified by XPS. ${ }^{16}$ The phase composition of tribo-oxides differs for these two coatings: considerably higher concentration of
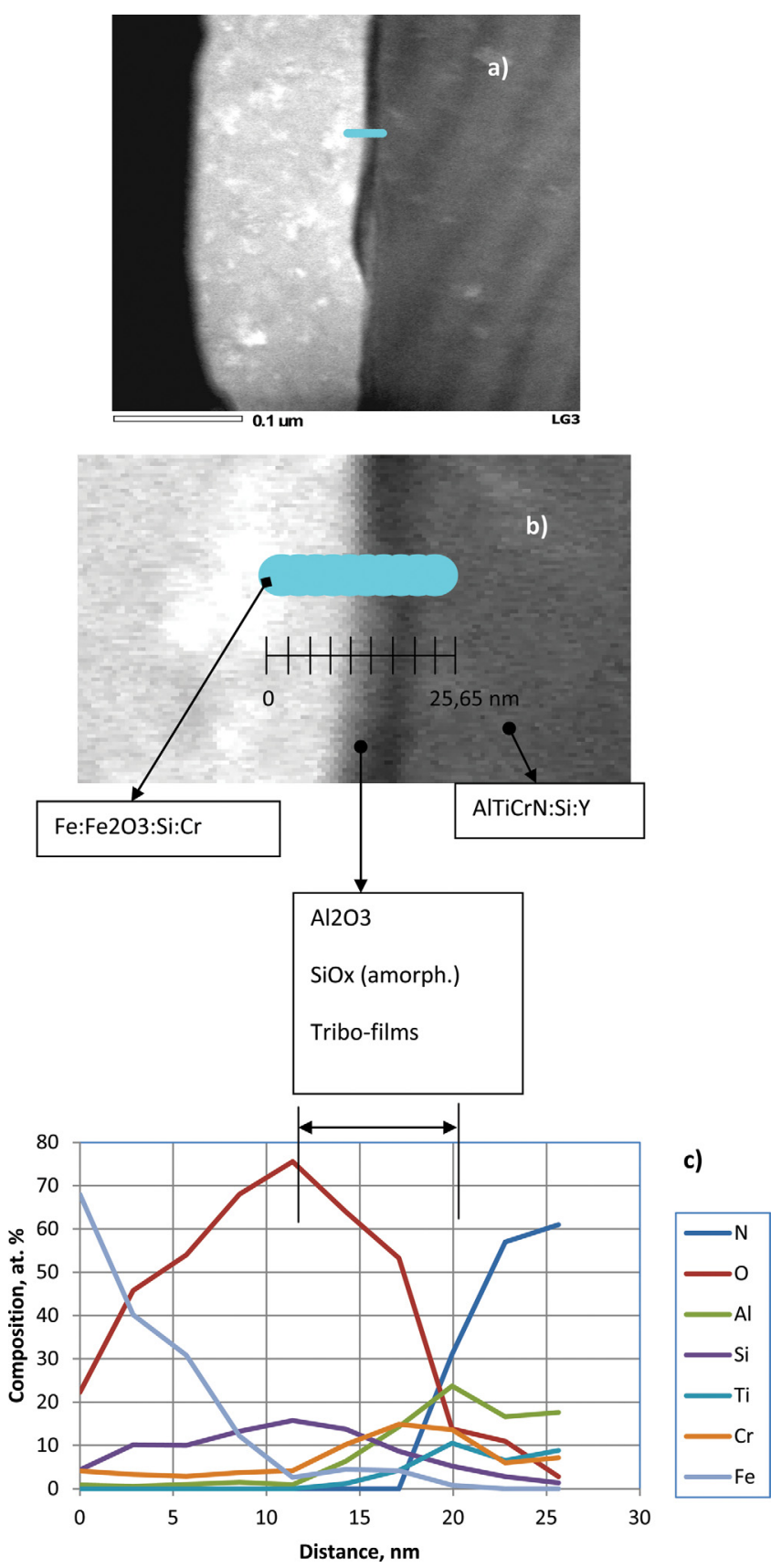

FIG. 7. (Color online) High annular angular dark field (HAADF)-STEM image (a)-(b) and EDAX profile (c) of the worn TiAlCrSiYN/TiAlCrN coating layer (see Fig. 6). EDX data was collected with the spot size of $1 \mathrm{~nm}$ and the step was 2-3 $\mathrm{nm}$. 
$\mathrm{Al}_{2} \mathrm{O}_{3}$ is formed during tribo-oxidation of multilayered coating (Fig. 4). As shown previously ${ }^{52}$ the aluminum rich $\mathrm{Ti}_{0.25} \mathrm{Al}_{0.65} \mathrm{Cr}_{0.1} \mathrm{~N}$ nano-layers are characterized by the higher oxidizing ability than $\mathrm{Ti}_{0.2} \mathrm{Al}_{0.55} \mathrm{Cr}_{0.2} \mathrm{Si}_{0.03} \mathrm{Y}_{0.02} \mathrm{~N}$ ones. Due to the contribution of more aluminum rich $\mathrm{Ti}_{0.25} \mathrm{Al}_{0.65} \mathrm{Cr}_{0.1} \mathrm{~N}$ nano-layers in the multi-layered coating, the amount of alumina films on the friction surface grows. The amplification of boundary diffusion caused by the increase of interfaces and grain boundaries in nanomultilayered coatings is also an important factor. ${ }^{53}$ Based on these results we can conclude that phase composition of the tribo-films formed on the friction surface is very complex. The different types of the tribo-oxides that are evident include: protective sapphire and mullite $\left(\mathrm{Al}_{6} \mathrm{Si}_{2} \mathrm{O}_{13}\right)$ triboceramics; lubricating polyvalent chromium oxides, nonprotective $\mathrm{TiO}_{\mathrm{x}}$ and $\mathrm{TiO}_{2}$ tribo-films.

The major factor that affects the structure and phase transformation within hard coating layer under extreme tribological conditions is amount of protective sapphire and mullite-like tribo-ceramics that are generated on the friction surface. This can be illustrated by the TEM investigations of the workpiece/tool interface for the cutting tools with adaptive TiAlCrSiYN monolayer and TiAlCrSiYN/ TiAlCrN multilayer coatings. Under high temperature frictional conditions, significant surface damage as well as grain size coarsening is taking place on the surface of the cutting tool with the monolayer TiAlCrSiYN coating (Fig. 5(a)). In contrast, TEM images of the workpiece/tool interface in the TiAlCrSiYN/TiAlCrN multilayer coating with better surface protection by sapphire/mullite tribofilms does not indicate significant surface damage (Figs. 4 and 5; Fig. 6). Grain size coarsening in this coating on the friction surface is minimal compared to the as deposited state (Fig. 5(b)). ${ }^{16,17}$

One of the principal features associated with cutting is a rapid increase in the dislocation density near the surface with the deformation being localized within a thin layer. Under extreme frictional conditions of cutting, this layer has a very fine-grained, close to amorphous structure (Fig. 6) that corresponds to previously obtained data. ${ }^{54-57}$ The increase in dislocation density in this local volume is accompanied by activation of the surface layers of the tool leading to further intensive interactions with the environment (tribooxidation). ${ }^{55-57}$ This results in the rapid formation of the tribo-films. At high temperatures of friction nitrogen is migrating from the surface and being replaced by oxygen (as a result of the tribo-oxidation process) as shown by EnergyDispersive X-Ray Spectroscopy (EDX) data (Fig. 7(c)). Figure 6 shows that the structure of the surface of the coated tool is mainly amorphous. The depth of the amorphous layer is around $\sim 10 \mathrm{~nm}$. Most probable phases within this layer indentified by EDX are protective alumina (sapphire) and
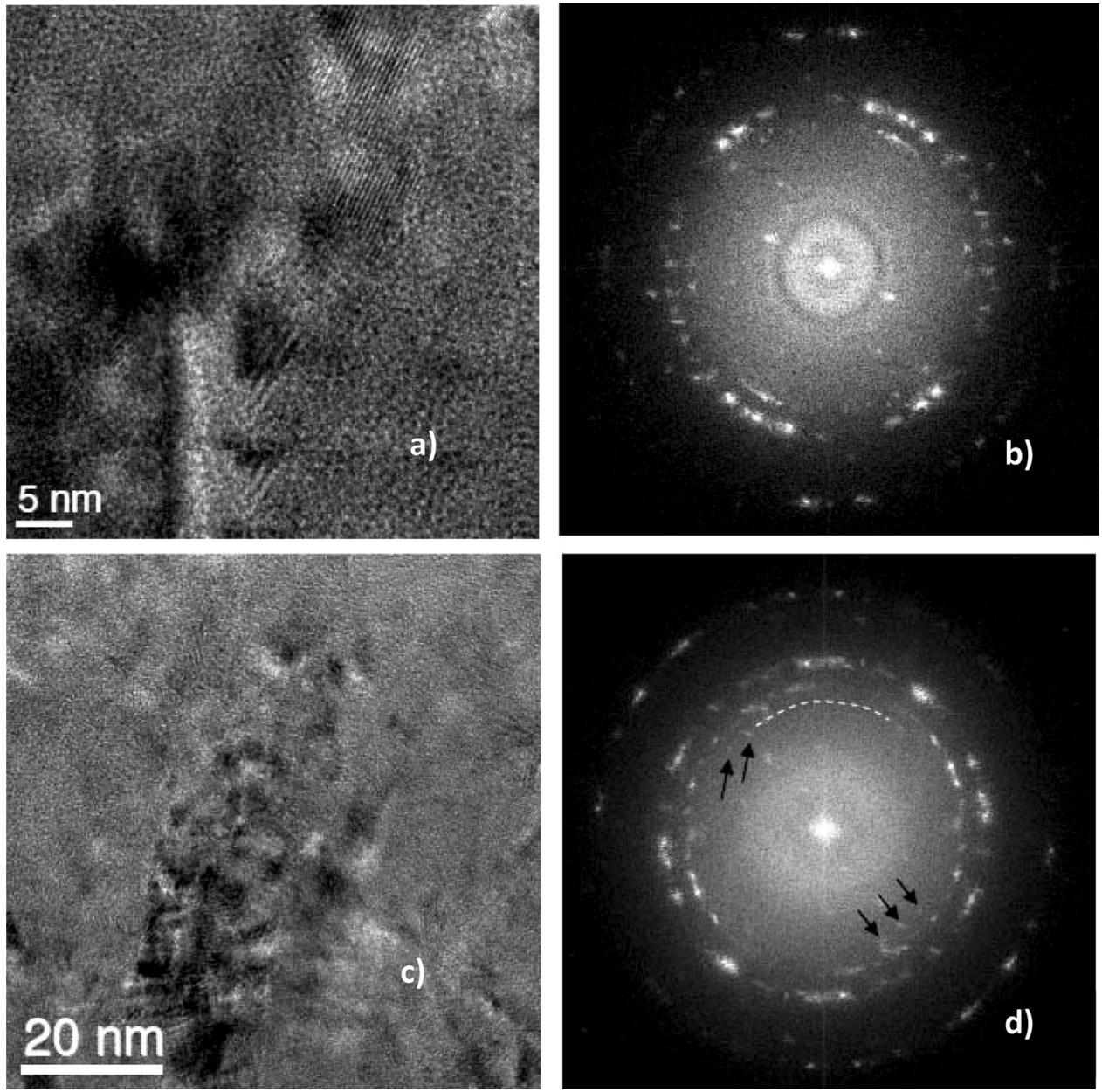

FIG. 8. Zero loss HRTEM image with SAED pattern inset of the worn TiAlCrSiYN/TiAlCrN coating layer (see Figs. 5 and 6): (a)-(b) $45 \mathrm{~nm}$ from the surface, no evidence of AlN hex; (c)-(d) $85 \mathrm{~nm}$ from the surface, small amount of the $\mathrm{AlN}_{\text {hex }}$ phase. 
some $\mathrm{SiO}_{x}$ phases that possess a combination of protective ${ }^{58}$ and high temperature lubricious properties ${ }^{59,60}$ (Fig. 7(c)).

The formation of the protective tribo-films together with a reduction in surface damage (Figs. 5 and 6) strongly influences the phase transformation within the layer of the coating during friction (Fig. 8). It was shown previously that the TiAlCrSiYN/TiAlCrN multilayer coating in the as-deposited state has a very minor amount of $\mathrm{AlN}_{\text {hex }}$ phase. ${ }^{16}$ It is hard to indentify $\mathrm{AlN}_{\text {hex }}$ phase within the surface layer of $40 \mathrm{~nm}$ (Figs. 8(a) and 8(b)) in the worn sample of the TiAlCrSiYN/ TiAlCrN multilayer coating in spite of growing $\mathrm{N}$ content (Fig. 7(c)). At bigger depth (of around $80 \mathrm{~nm}$ ) it is possible to find small amount of the phase that corresponds to AlN hex (100) $\sim 0.268 \mathrm{~nm}$ (Figs. 8(c) and 8(d)). Results of XANES analysis shown in Fig. 9 confirms TEM data presented in Fig. 8. The comparison of the line shape of the nitrogen signal in Fig. 9 clearly indicates that the inner layer of the worn coating with the tribo-films formed on the friction surface did not reach high temperatures. Feature B which is related to the first (most prominent peak from the h-AlN standard) is not predominant in the coating on the worn tool. However XANES analysis shows that during in situ heating of the

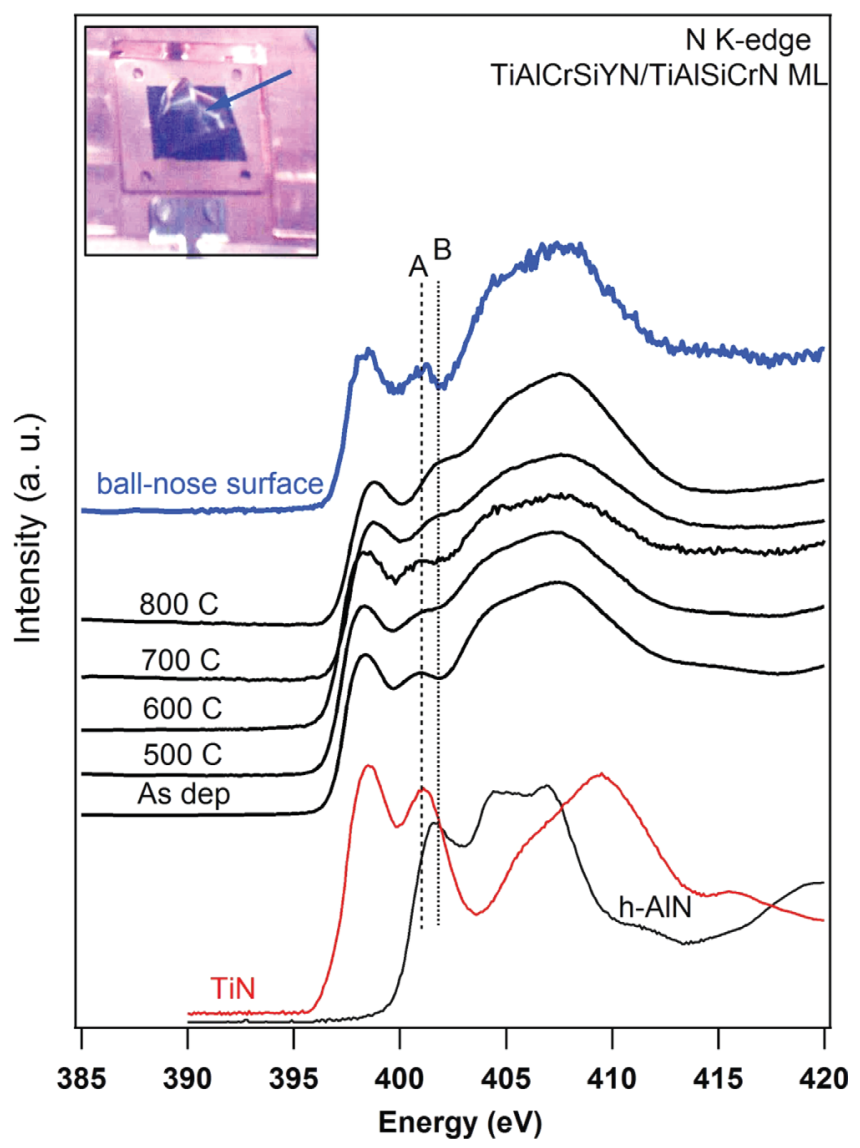

FIG. 9. (Color online) Partial fluorescence yield x-ray absorption spectra of $\mathrm{N}-\mathrm{K}$ edge after annealing in-vacuum of the TiAlCrSiYN/TiAlCrN multilayer coating at various temperatures: c-TiN and h-AIN N-K edge standards are presented here for comparison purposes in order to show the evolution in thermal decomposition of the TiAlCrSiYN/TiAlCrN multilayer coating. Features $\mathrm{A}$ and $\mathrm{B}$ of the nitrogen signal are related to the first (most prominent peaks of the c-TiN and h-AlN correspondingly). The inset shows the tip of the worn ball nose tool which was cut and placed on top of a cupper holder in order to acquire the XANES signal. coated layer in vacuum formation of $\mathrm{AlN}_{\text {hex }}$ phase at the temperatures above $600^{\circ} \mathrm{C}$ is quite significant (Fig. 9). XRD data of the samples with TiAlCrSiYN/TiAlCrN multilayer coating annealed in vacuum during $0.5 \mathrm{~h}$ at the temperatures 600 and $700{ }^{\circ} \mathrm{C}$ (Fig. 10) corresponds to XANES data presented in Fig. 9. XRD spectra in Fig. 10 show that at the temperatures of $700{ }^{\circ} \mathrm{C}$ phase de-composition begins and $\mathrm{AlN}_{\text {cubic }}$ as well as $\mathrm{AlN}_{\text {hex }}$ phases are starting to form. Moreover, grain coarsening is developing because diffused peak at 44 degrees transforms to a sharper peak. These results indirectly indicate that the temperature of the coating below the layer of the protective tribo-films is strongly reduced. This reduction in the temperature of the coating layer (probably down to around of $600^{\circ} \mathrm{C}$ ) is a cause of both low surface damage (Fig. 5) as well as low intensity of phase transformation (phase de-composition, Fig. 8) within the coating layer. The marked reduction in the formation of the non-beneficial $\mathrm{AlN}_{\text {hex }}$ phase prevents intensive coating damage under high temperatures. One more possible explanation of the reduced incoherent $\mathrm{AlN}_{\text {hex }}$ phase formation under operation is that the phase transformation is suppressed due to the high pressure on the friction surface during machinating of hardened H 13 steel. This phenomenon is more pronounced in multilayer coatings. ${ }^{61,62}$

Figure 11 presents micro-mechanical data for the both TiAlCrSiYN monolayer and TiAlCrSiYN/TiAlCrN multilayer coatings versus temperature up to $600{ }^{\circ} \mathrm{C}$. In the multilayer $\mathrm{TiAlCrSiYN} / \mathrm{TiAlCrN}$ coating the hardness appears stable $(27 \mathrm{GPa})$ to $500{ }^{\circ} \mathrm{C}$ and then drops a little at $600{ }^{\circ} \mathrm{C}$ but still remains quite high (22 GPa) (Fig. 11(a)). In contrast, the TiAlCrSiYN monolayer coating gradually reduces its hardness with temperature (Fig. 11(a)). The high temperature stable hardness of the TiAlCrSiYN/TiAlCrN coating could be related to the hindering of dislocation movement by the layer interfaces in the nano-multilayer coatings under loading. ${ }^{63,64}$ The TiAlCrSiYN/TiAlCrN multilayer coating also has significantly better load support (resistance to plastic deformation that scales with $\mathrm{H}^{3} / \mathrm{E}_{\mathrm{r}}{ }^{2}$ ratio, ${ }^{65-67}$ which is very high for this coating, especially at elevated temperatures (Fig. 11(c)). Our previous studies have noted that this parameter can show excellent correlation with the impact fatigue fracture resistance. ${ }^{16}$ It minimizes the probability of

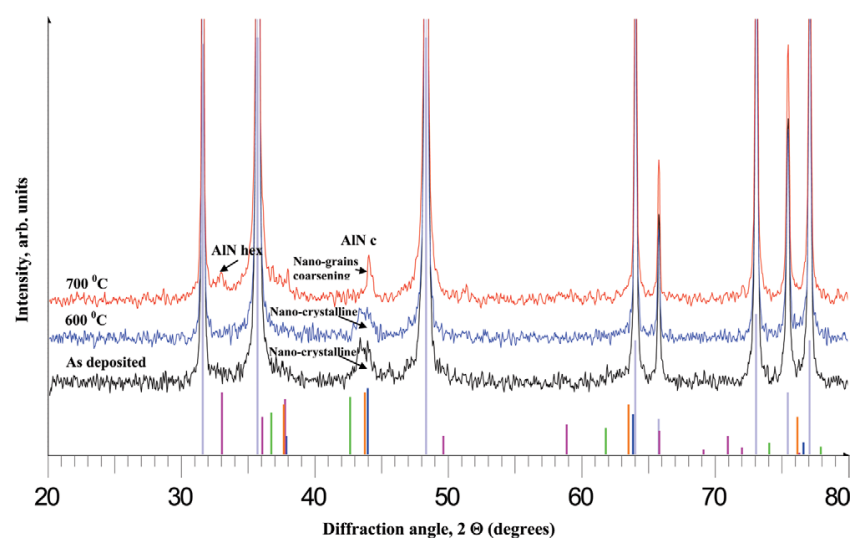

FIG. 10. (Color online) XRD data on TiAlCrSiYN/TiAlCrN multilayer coating before and after annealing at 600 and $700{ }^{\circ} \mathrm{C}$ correspondingly. 


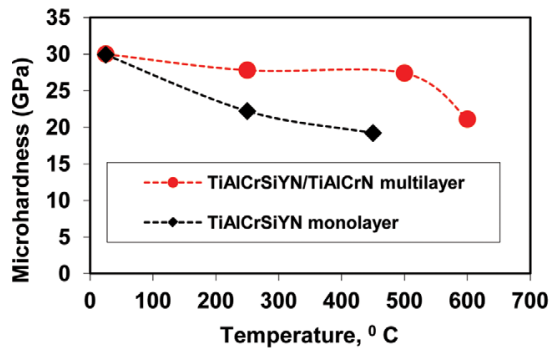

a)

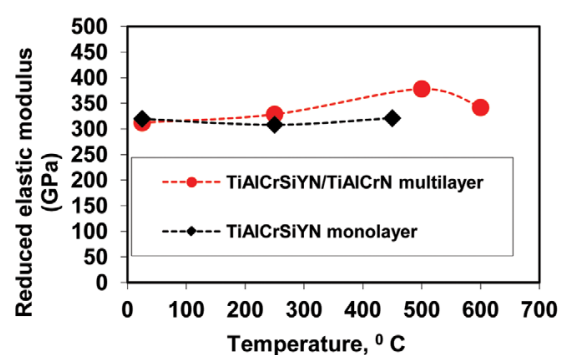

b)

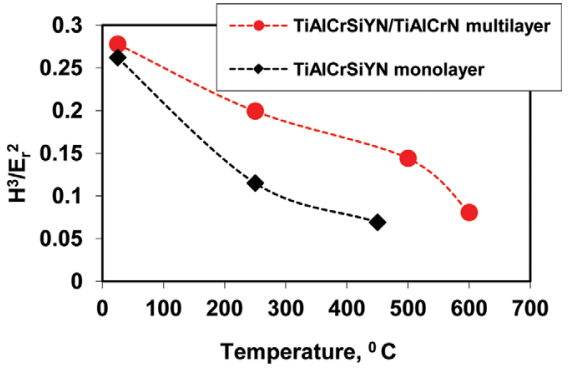

c)

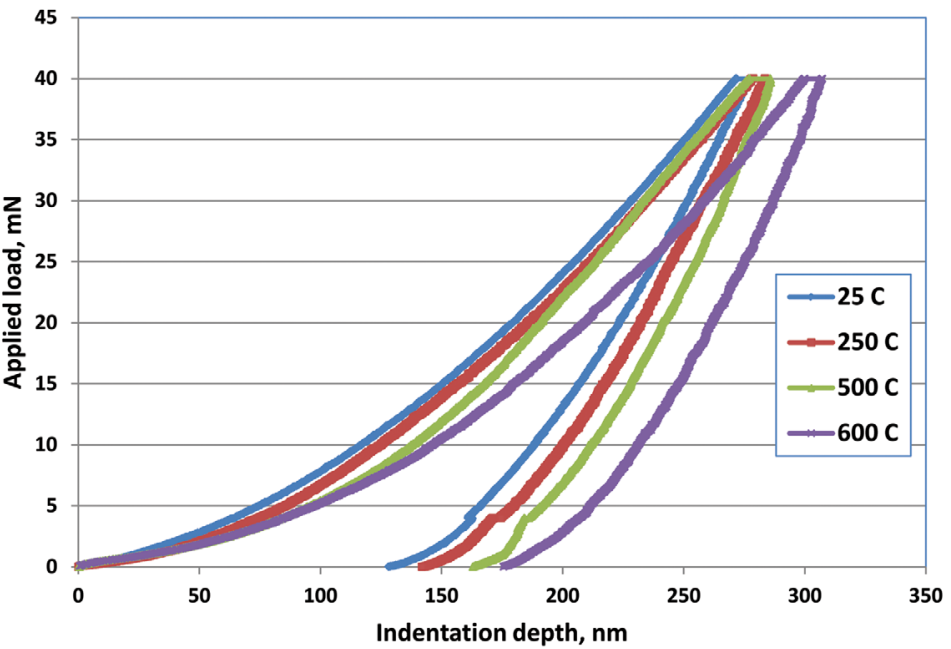

d)

FIG. 11. (Color online) Micro-mechanical properties of TiAlCrSiYN/TiAlCrN multilayer and TiAlCrSiYN monolayer coatings measured at room and elevated temperatures: (a) microhardness; (b) reduced elastic modulus; (c) $\mathrm{H}^{3} / \mathrm{E}_{\mathrm{r}}{ }^{2}$ ratio; (d) indentation curves at different temperatures.

initiating cracks in the first place under heavy load conditions, ${ }^{65}$ diminishes surface damage and improves wear resistance. ${ }^{16}$

\section{CONCLUSIONS}

Analytical modeling, including thermodynamic analysis and FEM modeling of heat conduction in the cutting zone combined with detailed experimental studies of the structure and properties allow the following mechanism of adaptability of hard nano-multilayer TiAlCrSiYN/TiAlCrN coating under extreme frictional conditions to be outlined. Formation of the highly protective sapphire and mullite-like tribo-films beneficially affects heat re-distribution on the friction surface of coated tool under extreme tribological conditions associated with dry ultra-speed machining of hardened $\mathrm{H} 13$ tool steel. The thermal barrier properties of these films largely prevent heat propagation into the body of the coated tools. The major physical-chemical processes during cutting start to be mainly concentrated within a very thin (nano-scale) surface layer. As a result of these tribo-films formation strong temperature gradient generates on the friction surface. Therefore, surface damaging processes within coating layer associated with grain coarsening are significantly diminished during friction and non-beneficial phase transformation (formation of $\mathrm{AlN}_{\text {hex }}$ phase) is reduced as well. High temperature stable hardness of the nano-multilayered coating also helps to withstand heavy loads under operation. Adaptive multilayer TiAlCrSiYN/TiAlCrN coating with higher amount of protective sapphire- and mullite-like surface tribo-films is therefore able to sustain strongly severing and extreme operating conditions.

${ }^{1} \mathrm{P}$. Wright and E. Trent, Metal Cutting, 4th ed., (Butterworth-Heinemann, Boston, 2000).

${ }^{2}$ J. Loffler, Surf. Coatings Technol. 68-69, 729 (1994).

${ }^{3}$ G. S. Fox-Rabinovich, S. C. Veldhuis, G. K Dosbaeva, K. Yamamoto, and A. I. Kovalev, J. Appl. Phys. 103, 083510-10 (2008).

${ }^{4}$ L. Ning, S. C. Veldhuis, and K. Yamamoto, Int. J. Mach.Tools Manuf. 48, 656 (2008).

${ }^{5}$ Y. Ning, M. Rahman, and Y. S. Wong, J. Mater. Proc. Tech. 13, 360 (2001).

${ }^{6}$ V. C. Venkatesh, D. Q. Zhou, and W. Xue, Annals of the CIRP 42(1), 631 (1993).

${ }^{7}$ W. Huang, Mater. \& Design. 23, 11 (2002).

${ }^{8}$ A. Amini, Y. He, and Q. P. Sun, Mater. Lett. 65, 464 (2011).

${ }^{9} \mathrm{~K}$. Holmberg and A. Matthew, Coating Tribology:Principles, Techniques and Application in Surface Engineering (Elsevier Science, Amsterdam, 1994).

${ }^{10} \mathrm{G}$. Fox-Rabinovich and G. Totten, Self-Organization During Friction: Advanced Surface Engineered Materials and Systems Design (CRC Press, and Francis Group, Boca Raton, NW, USA, 2006).

${ }^{11}$ P. H. Mayrhofer, C. Mitterer, L. Hultman, and H. Clemens, Progr. Mater. Sci. 51, 1032 (2006).

${ }^{12}$ G. S. Fox-Rabinovich, A. I. Kovalev, L. S. Shuster, S. C. Veldhuis, and I. S. Gershman, in Self-organization during friction: Advance Surface Engineered Materials and Systems Design, edited by G. S. Fox-Rabinovich and G. Totten (CRC Press, and Francis Group, Boca Raton, NW, USA, 2006), p. 231-297.

${ }^{13}$ I. Prigogine and D. Kondepudi, Modern Thermodynamics (John Wiley \& Sons, New York, 1999).

${ }^{14}$ W. König, R. Fritsch, and D. Kammermeier, Annals of the CIPR 41:49, (1992), p. 591-605. 
${ }^{15}$ W. Kalss, A. Reiter, V. Derflinger, C. Gey, and J. L Endrino, Int. J. Refract. Met. Hard Mater. 24, 399 (2006).

${ }^{16}$ G. S. Fox-Rabinovich, K. Yamamoto, B. D. Beake, A. I. Kovalev, M. H. Aguirre, S. C. Veldhuis, G. K. Dosbaeva, D. L. Wainstein, A. Biksa, and A. Rashkovskiy, Surf. Coat. Tech. 204, 3425 (2010).

${ }^{17}$ G. S. Fox-Rabinovich, B. D. Beake, K. Yamamoto, M. H. Aguirre, S. C. Veldhuis, and G. Dosbaeva, Surf. Coat. Tech. 21-22, 3698 (2010).

${ }^{18}$ S. Seifert, E. Litovsky, J. I. Kleiman, and R. B. Heimann, Surf. Coat. Tech. 11, 3404 (2006).

${ }^{19}$ D. A. Ditmars, S. Ishihara, S. Chang, G. Bernstein, and E. West, J. Res. Nat. Bur. Stand. 87, 159 (1982).

${ }^{20}$ B. Kostetsky, J. Friction and Wear 14, 773 (1993).

${ }^{21}$ L. Bershadsky, J. Friction and Wear 8, 1077 (1992).

${ }^{22} \mathrm{~N}$. Bushe and V. Kopitko Compatibility of Rubbing Surface (Science, Moscow, 1981).

${ }^{23} \mathrm{~N}$. Bushe and I. Gershman in Self-Organization During Friction: Advanced Surface-Engineered Materials and Systems Design, edited by G. Fox-Rabinovich and G. Totten (CRC Press, and Francis Group, Boca Raton, 2006), p. 59-81.

${ }^{24}$ I. Gershman and N. Bushe in Self-Organization During Friction: Advanced Surface-Engineered Materials and Systems Design, edited by G. Fox-Rabinovich and G. Totten (CRC Press, and Francis Group, Boca Raton, 2006) p. 13-58.

${ }^{25}$ L. D. Landau and E. M. Lifsitz, Statistical Physics (Nauka, Moscow, 1976), p. 118-144.

${ }^{26}$ I. Gershman and N. Bushe, Surf. Coat. Tech. 186, 405 (2004).

${ }^{27}$ N. P. Dubinin, Technology of the Metals (Mashgiz, Moscow, 1958), (in Russian).

${ }^{28}$ H. Engqvist, H. Hogberg, G. A. Botton, S. Ederyd, and N. Axén, Wear 239, 219 (2000).

${ }^{29}$ R. F. Brito, S. R. de Carvalho, S. M. M. de Lima e Silva, and J. R. Ferreira, Heat and Mass Transf. 36, 314 (2009).

${ }^{30}$ Y. C. Yen, A. Jain, P. Chigurupati, W. T. Wu, and T. Altan, Mach. Sci. Technol. 8, 305 (2004).

${ }^{31}$ D. Cahill, J. Appl. Phys. 93, 793 (2003).

${ }^{32}$ Y. C. Eugene and Y. Yen, Computer Simulation of Orthogonal Cutting Using a Tool with Multiple Coatings (ERC/NSM, The Ohio State University, 2003).

${ }^{33}$ M. Rhode, Int. J. Thermophys. 28, 1621 (2007).

${ }^{34}$ G. S. Fox-Rabinovich, A. I. Kovalev, L. S. Shuster, Y. F. Bokiy, G. K. Dosbaeva, D. L. Wainstein, and V. P. Mishina, Wear, Part 2, 214, 279 (1998).

${ }^{35}$ H. Schneider, J. Schreuer, and B. Hildmann, J. Europ. Ceram. Soc. 28, 329 (2008).

${ }^{36}$ Y.-C. Chen, X. Al, and C.-Z. Huang, Mater. Sci. Eng. B77, 221 (2000).

${ }^{37}$ G. Erkens, R. Cremer, T. Hamoudi, K. D. Bouzakis, I. Mirisidis, and S. Hadjiyiannis, Surf. Coat. Techn. 177-178, 727 (2004).

${ }^{38}$ T. C. Totmeier and W. F. Gale, eds., Smithells Metals Reference Book, 3rd ed. (Elsevier, Amsterdam), Vol. 177-178, pp. 727-734 (2004).
${ }^{39}$ J. P. Holman, Heat Transfer (McGraw-Hill, New York, 1997).

${ }^{40}$ J. Rech, A. Kusiak, and J. L. Battaglia, Surf. Coat. Tech. 186, 364 (2004).

${ }^{41}$ J. Rech, J. L. Battaglia, and A. Moisan, J. Mater. Process. Technol. 159, 119 (2005).

${ }^{42}$ A. Kuisiak, J. L. Battaglia, and J. Rech, Surf. Coat. Tech. 195, 29 (2005).

${ }^{43}$ W. Grzesik, M. Bartoszuk, and P. Nieslony, Int. J. Mach. Tools Manuf. 46, 651 (2006).

${ }^{44}$ J. L. Endrino, G. S. Fox-Rabinovich, R. Escobar Galindo, W. Kalss, S. Veldhuis, and L. Soriano, Surf. Coat. Technol. 204, 256 (2009).

${ }^{45}$ J. E. Krzanowski, S. Palacín, A. Gutiérrez, F. Schäfers, M. Mertin, and J. L. Endrino, Scripta Mater. 56, 1011 (2007).

${ }^{46}$ A. Somayji and P. B. Aswath, Tribol. Trans. 52, 511 (2009).

${ }^{47}$ J. Milhans, D. S. Li, M. Khaleel, X. Sun, Marwan S. Al-Haik, A. J. Harris, and H. Garmestani, J. Power Sources 196, 5599 (2011).

${ }^{48}$ T. I. Mah and K. S. Mazdiyasni, J. Amer. Cer. Soc. 66, 699 (1983).

${ }^{49}$ P. A. Lessing, R. S. Gordon, and K. S. Mazdiyasni, J. Amer. Cer. Soc. 58, 149 (1975).

${ }^{50}$ M. I. Osendi and C. Baudín, J. Europ. Cer. Soc. 16, 217 (1996).

${ }^{51}$ G. S. Fox-Rabinovich, K. Yamomoto, S. C. Veldhuis, A. I. Kovalev, and G. K. Dosbaeva, Surf. Coat. Tech. 200, 1804 (2005).

${ }^{52}$ G. K. Dosbaeva, S. C. Veldhuis, K. Yamamoto, D. S. Wilkinson, B. D. Beake, N. Jenkins, A. Elfizy, and G. S. Fox-Rabinovich, Int. J. Refract. Met. Hard Mater. 28, 133 (2010).

${ }^{53}$ A. Kovalev, D. Wainstein, A. Rashkovskiy, G. Fox-Rabinovich, S. Veldhuis, M. Aguirre, and K. Yamamoto, Surf. Interf. Anal. 42, 1368 (2010).

${ }^{54}$ Z. Xingzhong, L. Jiajun, Z. Baoliang, M. Hezhou, and L. Zhenbi, Cer. Int. 25, 309 (1999).

${ }^{55}$ Y. Kabaldin, N. Kojevnikov, and K. Kravchuk, J. Frict. Wear 11, 130 (1990).

${ }^{56}$ Y. Kabaldin, J. Frict. Wear 10, 8001 (1989).

${ }^{57}$ Y. Kabaldin, Structure, Strength and Wear Resistance of Composite Tool Materials (Vladivostok, Dalnauka, 1996).

${ }^{58}$ J. B. Choi, K. Cho, M.-H. Lee, and K. H. Kim, Thin Solid Films 447-448, 365 (2004).

${ }^{59}$ F. Honda and T. Saito, Appl. Surf. Sci. 92, 651 (1996).

${ }^{60}$ L. D. Bandcroft, G. M. Kasrai, M. Fleet, R. Secco, and X. Feng, Amer. Mineral. 79, 622 (1994).

${ }^{61}$ A. Horling, L. Hultman, M. Oden, J. Sjolen, and L. Karlsson, J. Vac. Sci. Tech. A: Vacuum, Surfaces, and Films 20, 1815 (2002).

${ }^{62}$ L. Chen, Y. Du, P. H. Mayrhofer, S. Q. Wang, and J. Li, Surf. Coat. Technol. 202, 5158 (2008).

${ }^{63}$ P. C. Yashar and W. D. Sproul, Vacuum 55, 179 (1999).

${ }^{64}$ E. Arzt, Acta. Mater. 46, 5611 (1998).

${ }^{65}$ S. Hassani, M. Bielawski, W. Beres, L. Martinu, M. Balazinski, and J. E. Klemberg-Sapieha, Surf. Coat. Technol. 203, 204 (2008).

${ }^{66}$ S. J. Bull and A. M. Jones, Surf. Coat. Technol. 78, 173 (1996).

${ }^{67}$ B. D. Beake, G. A. Bell, S. R. Goodes, N. J. Pickford, and J. F. Smith, Surf. Eng. 26(1-2), 37 (2010). 